\title{
What EYFA Is and Does
}

$T^{\prime}$ he acronym EYFA stands for the European Youth Forest Action, which is a Europe-wide network of young people, with strong representation from both the eastern and western sides of the continent, who are concerned about the increasing destruction of their own and our world's environment.

EYFA is an umbrella organization. We believe that it is necessary to bring grassroots movements together because the preservation of the environment is an issue of vital importance for everybody. Europe is our homeland and we want to bridge its official borders so that nobody will feel that he or she is an outsider inside Europe. We believe in a future Europe that will be a community of different cultures enriching and cooperating with one another in the name of our common peaceful future. We believe in a world where Nature will be taken care of and there will be respect between all human beings as well as between Nature and Humankind.

EYFA represents the new generation that is coming up: a generation that is able to combine idealism with an active commitment and strong will to achieve its ideals. It was started in 1986 from a Swedish initiative to 'Save the forests of Europe'. Since then it has expanded its Europewide network to do much more. The young people in our network are organizing a wide variety of activities that range from seminars on such topics as biodiversity and ecofeminism to actions such as protesting against the excessive shipping of tropical timbers and trying to stop the building of new nuclear power-plants in Eastern Europe.

\section{Cooperation and Exchange}

International cooperation is a common theme for us. EEEP (Eastern European Exchange Programme) brings Easterners to our Western projects and Westerners to our Eastern ones. These connections have created friendships and relationships, not to mention such projects as SNEEEZ (Stop Nuclear Energy in the Eastern European Zone), SNORE (Support Network on Renewable Energy), and EcoAgro (Ecological Agriculture in Central Europe). Our newest (and one of the most significant) projects is the running of the Sunflower Anti-war Campaign in Zagreb, Croatia. There we do independent refugee work, non-violent training, and seek creative ways to end the most horrible war.

This year there is more: a women's project concerning the role and impact of women in the environmental move- ment; an anti-racist campaign that will end up with a big festival in July, in Magdeburg, Germany; and a permanent communities' project that aims at networking the existing international communities and setting up new ones. This last project strikes at the core of EYFA's convictions that such self-sustaining biological communities can offer a true alternative for the world's future.

\section{Ecotopia}

In line with the objective of developing self-sustaining biological communities, is the biggest activity organized by EYFA: an annual summer ecological camp, 'Ecotopia'. This represents an attempt at developing an alternative, sustainable and environmentally-friendly way of life. We eat vegetarian food, use solar panels as a source of energy, separate and recycle our waste, and use bicycles instead of cars. We try to do as many things as possible by ourselves, with our own hands; we also endeavour to solve our problems together by encouraging close circles of collaboration.

Workshops on acute environmental problems are held in Ecotopia. Last year, for example, our major theme was 'Renewable versus Nuclear Energy'. So far, Ecotopia has taken place in Germany (1989), Hungary (1990), Estonia (1991), and Bulgaria (1992).

An essential part of our functioning is the ECO exchange-rate system which we have introduced: $1 \mathrm{ECO}$ is 1 DM but also 5 roubles or 3,000 zlotys, for example. In that way each of the participants pays the same amount from his or her personal income for food and other necessities.

This year our dream village is being built in Southern France, around the ruins of the castle St Barthelemy in the Pyrenees, where small wooden houses are to be built, so that our one-month camp can turn into a permanent Ecotopia with the help of donors to the worthy cause of helping enterprising young people to show, by their own example, how communities could live widely in an ecologically sustainable manner.

\section{Mariana Kosturkova, Bulgarian Organizer \\ European Youth Forest Action (EYFA) \\ Posthox 566 \\ 6130 AN Sittard \\ The Netherlands.}

Tel, +31 46-513045

Fax: $+3146-516460$.

\section{Increased Stress on the Butterfly Fauna of the Andaman and Nicobar Islands}

$\mathrm{T}$ The Andaman and Nicobar Islands were formed about 63 million years ago by a combination of tectonic movement of the Earth, volcanic activity, coral formation, and rising of the sea-level, with favourable environmental conditions for the development of an insular flora and fauna which in due course came to include a goodly percentage of endemics. The first degradation of the environment was noted near the end of the 18th century at Port Cornwallis, but this was not accepted by Nature. A second degradation was noted in 1858 around the British penal settlement at Port Blair.

After India gained independence, for a long time the settlements and development activities responsible for environmental degradation were not serious. But in the past decade different development schemes have threatened the environmental stability of these islands, and have attracted many scientists to study the ecological impact of human population, which has already exceeded the bearing capacity of the Bay Islands. Along with flora, the fauna of these islands is also affected by agriculture, monoculture, agro-forestry, hu- man settlements, immigration, and the development of tourism.

Among invertebrates, the insects form the major part of the fauna. Most beautiful are the butterflies, which are apt to be very specific to their food-plants. An attempt has been made to study the impact of environmental degradation on the butterfly fauna of these islands, where it seems that the extinction of one species could affect 20 species of plants, with serious consequences on these tropical evergreen islands. Threats to the 236 taxa of butterflies identified from the Andaman and Nicobar Islands come mainly from forest clearance for agriculture, human settlements, wood-based industries, and tourism. As all these seem to be increasing, the future bodes bleak indeed.

T.C. KHATRI
J.N. Government College
Port Blair 744104
Andamans
India.

